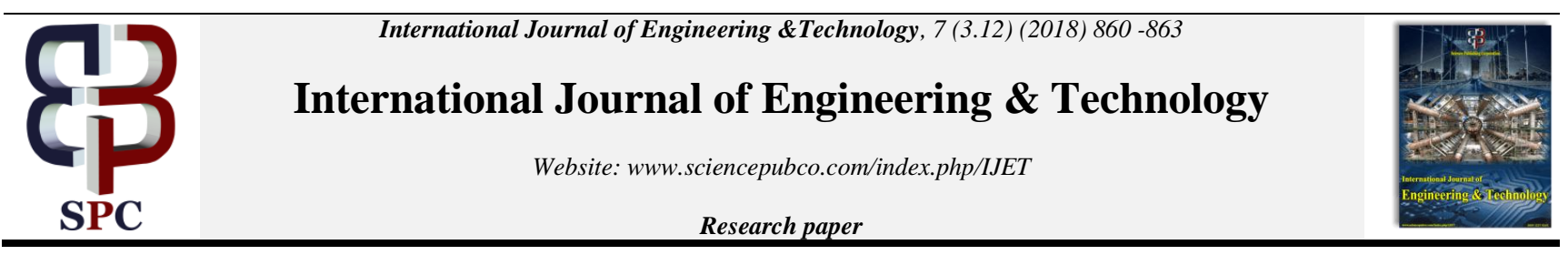

\title{
Study on Self-Cleaning Concrete Using Nano-liquid $\mathrm{TiO}_{2}$
}

\author{
T.Vignesh ${ }^{1}$, A.Sumathi ${ }^{2}$, K. Saravana Raja Mohan ${ }^{3}$ \\ School of Civil Engineering, SASTRA Deemed University, Thanjavur-613401 \\ *Coressponding Author Email: sumathi@civil.sastra.edu
}

\begin{abstract}
The present work explores to study the compressive strength and self-cleaning properties of the concrete by the applications of nanoliquid $\mathrm{TiO}_{2}$ on fresh concrete with different dosages $(0,2.5,5.0,7.5 \mathrm{ml})$ and single, double, and triple layer coating of nano-liquid Tio on the hardened concrete surfaces. Cement was partially replaced with Fly ash by In this study cement was replaced with $30 \%$ fly ash and to examine self cleaning properties of concrete by using Rhodamine-B dye (RhB) discoloration test under Sunlight/UV light visual observation. Concrete samples with photocatalytic nano-liquid $\mathrm{Tio}_{2}$ was mixed with fresh concrete (NF) showed enhanced compression strength by increasing the dosages when compared to the nano-liquid $\mathrm{Tio}_{2}$ was coated on the surface of the hardened concrete (NH). Self cleaning ability of NH of samples showed better results in cleaning ability than NF samples.
\end{abstract}

Key words: Self-cleaning concrete, Fly ash, Nano-liquid Tio, Compression Test, Rhodamine-B dye (RhB).

\section{Introduction}

Nowadays pollution plays the major role in mass destruction in environment, mainly air pollution. It causes serious problem in human beings as well as building aesthetic appearance. To overcome this, Photocatalytic materials such as titania $\left(\mathrm{TiO}_{2}\right)$ is added to the concrete thus self-cleaning properties can be determined. In this concrete the photocatalysts will be accelerated by ultraviolet (UV) radiation and it decomposes the organic particles present on the surface of the concrete.

Nanotechnology is well known that emerging research field and has a great impact in the field of construction materials [1]. Combination of Fly ash with nanoparticles has been shown that the improvement in the mechanical properties of concrete and also in its microstructure[2]. In 1973 botanist Wilhelm Barthlott found the principle behind in self-cleaning property. Due to its phocatalytic action the pollutants are removed with the addition of $\mathrm{TiO}_{2}$ on the hydrophilic and crystalline structure $[5,7]$.

This concrete is involved in Photocatalytic reaction which contributes to the decomposition of volatile organic compounds (VOCs). $\mathrm{TiO}_{2}$ react with the light and heat strikes the concrete surfaces, Photocatalytic efficiency can be increased and to shatter the dirt into the basic oxygen, water, $\mathrm{CO}_{2}$, nitrate and sulphate molecules [4]. From the ability of rhodamine-B discoloration the photocatalytic properties of the materials can be evaluated and exposed to artificial sunlight [3]. In the presence of UV light, photocatalysts helps to convert air pollutants from toxic to lesser toxic forms. Thus, contaminants and impurities are removed from the surrounding environment [6].

\section{Experimental Investigations}

\subsection{Materials}

\subsubsection{Cement}

Ordinary Portland Cement (OPC) 53 grade that conforming [8] was used in this study. The specific gravity of the cement is 3.12 . The chemical composition of cement is presented in Table 1 .

\subsubsection{Fly ash}

Class C fly ash was procured from Neyveli Lignite Corporation Limited, Neyveli, Tamilnadu and it is used as a replace in percentages of weight portion in cement content confirming [9]. The chemical composition of FA is presented in the Table 1. The specific gravity of Fly ash is 2.52 .

\subsubsection{Nano-Liquid Tio,}

Nano-Liquid $\mathrm{TiO}_{2}$ was obtained from Nano research laboratory Jamshedpur, India. Nano particles (anatase type) of purity $99 \%$ with average particle size of 5-10 nm were used. It has the appearance of colourless \& milky type water emulsion with slight odour of density $0.25 \mathrm{~g} / \mathrm{cm}^{3}$. Nano-Liquid has viscosity of $20 \mathrm{mpa}$ $\mathrm{S}$ and has $\mathrm{pH}=7.1$. 
Table 1: Chemical composition of Cement and Fly ash

\begin{tabular}{|c|c|c|c|c|}
\hline Mix Designation & $\begin{array}{c}\text { Cement +Fly ash } \\
(\boldsymbol{\%})\end{array}$ & $\begin{array}{c}\text { Nano-Liquid Tio } \\
\text { Coating }\end{array}$ & $\begin{array}{c}\text { Fine Aggregate-FA } \\
(\boldsymbol{\%})\end{array}$ & $\begin{array}{c}\text { Coarse Aggregate-CA } \\
(\boldsymbol{\%})\end{array}$ \\
\hline $\mathrm{CM}$ & $70+30$ & - & 100 & 100 \\
\hline $\mathrm{NF} 1$ & $70+30$ & Single layer & 100 & 100 \\
\hline $\mathrm{NF} 2$ & $70+30$ & Double layer & 100 & 100 \\
\hline $\mathrm{NF3}$ & $70+30$ & Triple layer & 100 & 100 \\
\hline
\end{tabular}

\subsubsection{Coarse Aggregate (CA) and Fine Aggregate (FA)}

Locally available natural coarse aggregate (CA) passing through $20 \mathrm{~mm}$ sieve and retained in $12 \mathrm{~mm}$ sieve were used with specific gravity of 2.75 . The natural river sand with specific gravity of 2.68 which has fineness modulus of 2.64 was used in this study. To ensure that the sand is free from foreign particles. The FA which passing through $2.36 \mathrm{~mm}$ sieve and retained in $1.18 \mathrm{~mm}$ sieve were used that confirming [10].

\subsubsection{Chemical Admixtures}

Super plasticizers were added to improve workability of concrete. CERAPLAST 300- RS (G) Modified high performance admixture for ready mixed concrete. It shows excellent workability retention even in extreme temperatures. It improves durability, reduces heat of hydration even with very high strength cements.

\section{Methodology}

\subsection{Details of Specimens}

The cube specimens of $100 \times 100 \times 100 \mathrm{~mm}$ were cast for Control Mix (CM) with $30 \%$ replacement of binder (cement) by fly ash. The cement percentage was kept constant for all mix proportions at $70 \%$ and no replacement has been carried out with FA and CA. Nano-Liquid $\mathrm{TiO}_{2}$ was mixed with fresh concrete (NF) with dosages of $(2.5,5.0,7.5 \mathrm{ml})$ and single, double and triple layer coating on the surface of hardened concrete $(\mathrm{NH})$.

\subsection{Mix Design and Proportions}

M30 grade of cement with 30\% replacement of fly ash and adding nano-liquid $\mathrm{Tio}_{2}$ of different dosages. CM consists of cement, fly ash, natural fine \& coarse aggregates, water and super plasticizer. Nano-liquid dosages were labelled as NF1 to NF3 (mixing with fresh concrete), NH1 to NH3 (spraying on hardened concrete) respectively. The cement and fly ash for various mixes was 369 $\mathrm{kg} / \mathrm{m}^{3}$. w/b ratio was 0.40 along with a superplasticizer, fly ash content was $111 \mathrm{~kg} / \mathrm{m}^{3}$, FA was $761.1 \mathrm{~kg} / \mathrm{m}^{3}$, CA was $1242 \mathrm{~kg} /$ $\mathrm{m}^{3}$ and superplasticizer was $4.6 \mathrm{~kg} / \mathrm{m}^{3}$.The medium workability of the concrete was observed from slump test in the range from 50 $\mathrm{mm}$ to $90 \mathrm{~mm}$. The concrete sample subjected to slump test is shown in fig.1. The mix proportions of samples are presented in the Table 2 and Table 3.

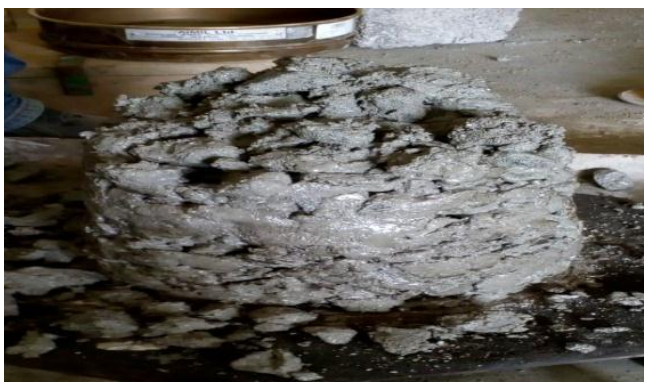

Fig.1: Concrete Slump
Table 2: Mix proportion percentages of Cement + Fly ash with NF samples

\begin{tabular}{|c|c|c|}
\hline \multirow{2}{*}{ Formula } & \multicolumn{2}{|c|}{ Concentration (\%) } \\
\cline { 2 - 3 } & Cement & Class C Fly ash \\
\hline $\mathrm{CaO}$ & 69.00 & 21 \\
\hline $\mathrm{SiO}_{2}$ & 24.91 & 40 \\
\hline $\mathrm{Al}_{2} \mathrm{O}_{3}$ & 5.85 & 18 \\
\hline $\mathrm{Fe}_{2} \mathrm{O}_{3}$ & 0.20 & 6 \\
\hline $\mathrm{MgO}_{\mathrm{Na}} \mathrm{O}$ & 0.04 & 2 \\
\hline $\mathrm{Na}_{2} \mathrm{O}$ & - & 5.8 \\
\hline Loss on Ignition & - & 0.3 \\
\hline
\end{tabular}

Table 3: Mix proportion percentages of Cement + Fly ash with $\mathrm{NH}$ samples

\begin{tabular}{|c|c|c|c|c|}
\hline $\begin{array}{c}\text { Mix } \\
\text { Designatio } \\
\text { n }\end{array}$ & $\begin{array}{c}\text { Cement } \\
\text { +Fly ash } \\
(\%)\end{array}$ & $\begin{array}{c}\text { Nano- } \\
\text { Liquid Tio } 2 \\
(\mathbf{m l})\end{array}$ & $\begin{array}{c}\text { Fine } \\
\text { Aggregate } \\
\text {-FA (\%) }\end{array}$ & $\begin{array}{c}\text { Coarse } \\
\text { Aggregate } \\
\text {-CA (\%) }\end{array}$ \\
\hline $\mathrm{CM}$ & $70+30$ & 0 & 100 & 100 \\
\hline $\mathrm{NF} 1$ & $70+30$ & 2.5 & 100 & 100 \\
\hline $\mathrm{NF} 2$ & $70+30$ & 5.0 & 100 & 100 \\
\hline $\mathrm{NF3}$ & $70+30$ & 7.5 & 100 & 100 \\
\hline
\end{tabular}

\section{Testing of Specimen}

\subsection{Compressive Strength Test}

The study reported that the $\mathrm{TiO}_{2}$ nanoparticles that are partially added to the cement shows increase in strength of the cement mortar [4]. The most of the case compressive strength test clearly indentify the structural design and concrete characteristic property. The three series of concrete mix samples $\mathrm{CM}, \mathrm{NF}, \mathrm{NH}$ were tested in ACTM of $3000 \mathrm{kN}$ capacity for different curing periods of concrete are 7, 14 and 28 days that confirming [11]. The compressive test set up is shown in Figure 1.

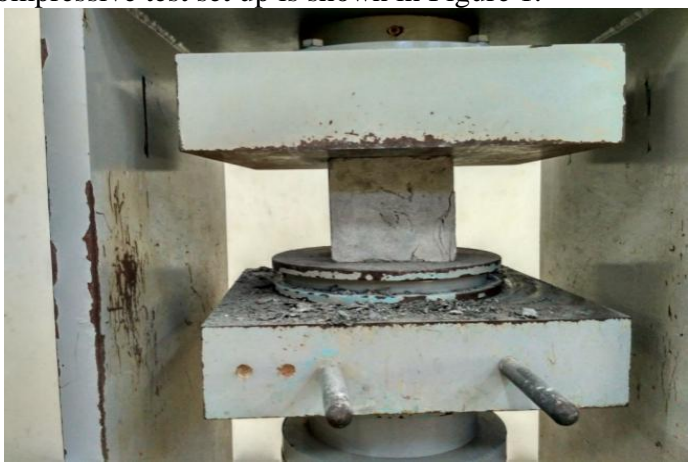

Fig. 2: Compressive Strength Test

\subsection{Rhodamine B Discoloration Test}

In order to determine the self-cleaning ability of the concrete by means of discoloration test. The rhodamine-B solution with concentration of $0.005 \mathrm{~g} / \mathrm{l}$ was prepared by dissolving $1.5 \mathrm{mg}$ of $\mathrm{RhB}$ powder in $30 \mathrm{ml}$ of distilled water applying on surfaces subjected to irradiation under UV light or solar light. The 
discoloration of rhodamine-B under natural sunlight up to 120 minutes of irradiation has been conducted [4]. Every 20 minutes $\mathrm{NF}$ and $\mathrm{NH}$ concrete samples were observed visually to find the degradation of $(\mathrm{RhB})$ on the concrete surfaces. Figure 3.1a), Figure 3.1b) and Figure 3.2a), Figure 3.2b) shows the discoloration test consist of 4 different concrete samples.

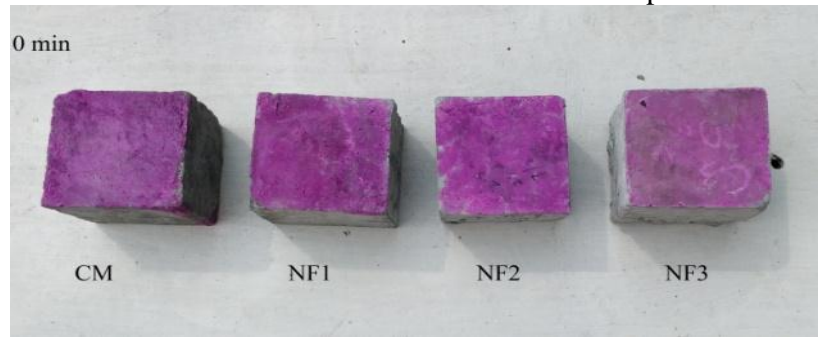

Fig. 3.1: (a) NF samples- initial stages

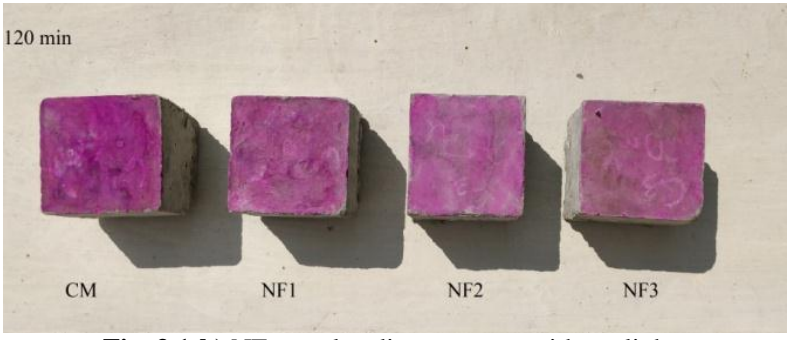

Fig. 3.1:b) NF samples-direct contact with sunlight.

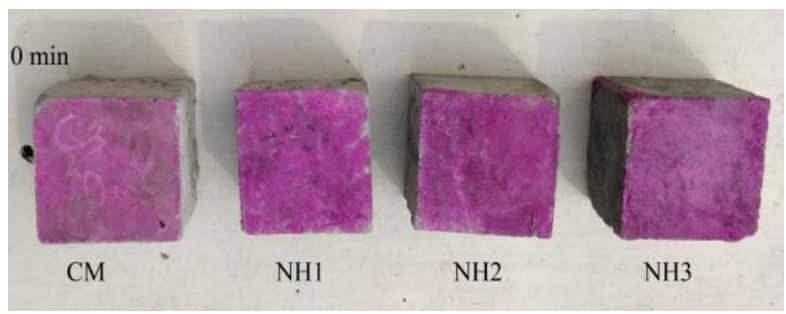

Fig. 3.2: a) NH samples are at initial stages

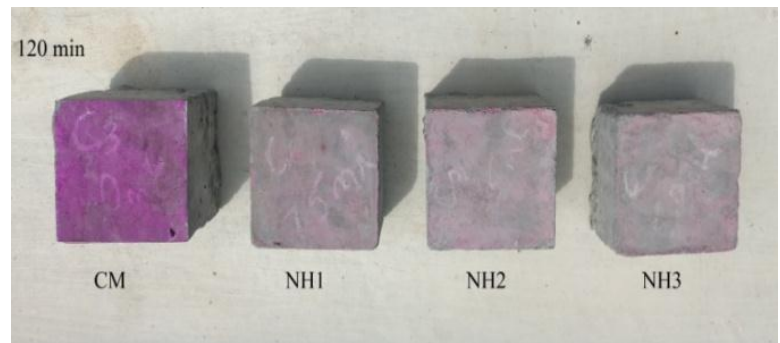

Fig. 3.2: b) NH samples are direct contact with sunlight.

\section{Results and Discussion}

From the total weight of the mix $70 \%$ was cement and remaining $30 \%$ was fly ash in addition to different dosages of nano-liquid $\mathrm{Tio}_{2}(0,2.5,5.0,7.5 \mathrm{ml})$ on NF samples and (single, double and triple layer coating of nano-liquid $\mathrm{Tio}_{2}$ ) on $\mathrm{NH}$ samples respectively. Both compressive strength and discoloration test same mix proportion was followed.

\subsection{Compressive strength}

The compressive strength was determined for the concrete cube samples for each mix proportions at different curing periods were listed in Table 3. Three cubes were cast for every mix proportions of different curing period are 7 days, 14 days and 28 days and average compressive strength were calculated. The results show that the nano-liquid $\mathrm{TiO}_{2}$ particles added concrete had appreciably higher compressive strength comparable to that of the normal concrete. The increase in nano-liquid $\mathrm{TiO}_{2}$ content there is gradual increase in strength as the pores has been filled with $\mathrm{TiO}_{2}$ because of that strength is increased. The average compressive strength of early (after 7 days curing) mix NF1, NF2, NF3 was found to be increased in strength when compared to $\mathrm{CM}$ (Control Mix) by $45.9 \%, 51.3 \%$ and $52.5 \%$ respectively. The compressive strength was determined after 14 days curing shown increased in percentage of $24.47 \%, 31.2 \%$ and $33.66 \%$ for the respective mix NF1, NF2 and NF3. Similarly, after 28 days curing the shown increased in percentage of $3.36 \%, 12.47 \%$ and $15.03 \%$ for the respective mix NF1, NF2 and NF3. It can be seen that there is a minute changes in compression strength of $\mathrm{NH}$ samples when compared to $\mathrm{CM}$ because nano-liquid was coated after curing period of 28 days. Since the concrete attained the compressive strength of $95 \%$ and also after 48 hours the specimen were tested with multiple layer of coatings on it. The nano-liquid penetrated only few millimeters in the hardened concrete.

Table 3: Compression Test Results.

\begin{tabular}{|c|c|c|c|c|}
\hline Mix Designation & $\begin{array}{c}\text { Cement +Fly ash } \\
(\boldsymbol{\%})\end{array}$ & $\mathbf{3}$ days & $\mathbf{1 4}$ days & $\mathbf{2 8}$ days \\
\cline { 3 - 5 } & $70+30$ & 22.83 & 28.31 & 35.92 \\
\hline CM & $70+30$ & 33.31 & 35.24 & 39.28 \\
\hline NF1 & $70+30$ & 34.56 & 37.15 & 40.40 \\
\hline NF2 & $70+30$ & 34.82 & 37.84 & 41.32 \\
\hline NH3 & $70+30$ & 23.12 & 27.50 & 34.86 \\
\hline NH2 & $70+30$ & 22.56 & 28.82 & 35.61 \\
\hline NH3 & $70+30$ & 21.43 & 28.63 & 35.38 \\
\hline
\end{tabular}




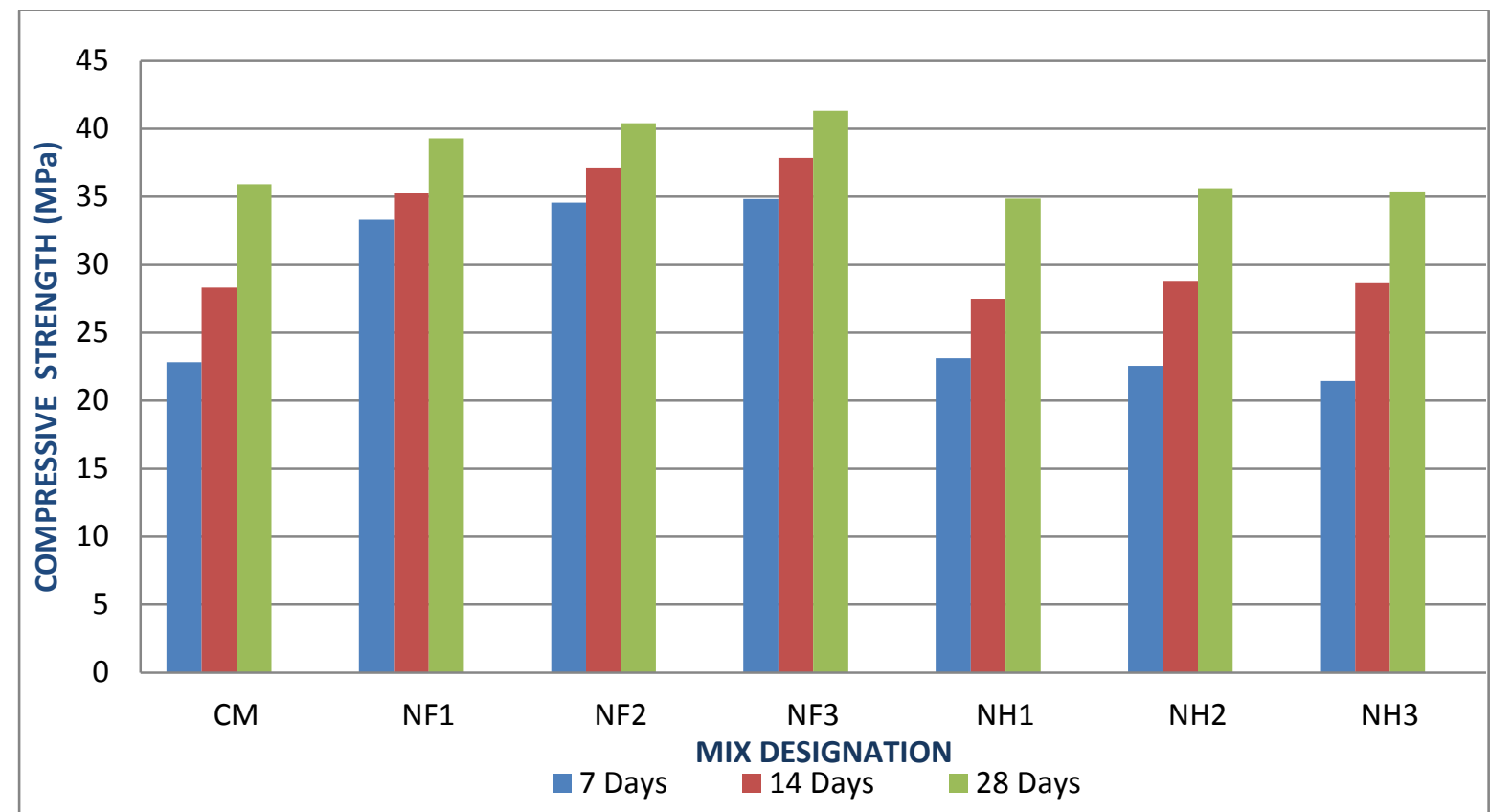

Fig. 3: Variation in Compressive Strength

\subsection{Discoloration Test}

After 120 minutes of visual observation concrete samples $\mathrm{NH}$ shown better cleaning ability than NF. Due to the variation in solar light discoloration is not achieved effectively. But the triple layer coated samples shown better cleaning ability when compared to single and double layer nano coating. For a better photocatalytic reaction conduct the discoloration test in UV light irradiation. In that coating Nano-Liquid $\mathrm{Tio}_{2}$ mixed with concrete or mortar remains unutilized because it is only effective in light irradiation. So adding nano-liquid to the building surfaces by coating or mixing with white cement for direct contact and exposed to the pollutants.

\section{Conclusion}

From the results of overview on self-cleaning concrete, the detailed conclusions were presented as follows.

- Concrete samples NF1, NF2, and NF3 yielded higher compression strength than the reference sample by increasing the nano-liquid dosages.

- NH samples didn't show any improvement in strength when nano-liquid coated on hardened concrete surface.

- Rhodamine-B discoloration on the surfaces of concrete samples NF and NH through visual observation showed the good self-cleaning properties of concrete containing nano-liquid $\mathrm{Tio}_{2}$. In that triple layer nano-liquid coating showed better cleaning ability than single and double layer coating.

- For a better photocatalytic reaction of NH and NF samples discoloration test should be carried out in UV light irradiation.

\section{References}

[1] Kamal Gad Sharobim and Hassan Ahmed Mohammedin. "The effect of Nano-liquid on the properties of hardened concrete", Housing and Building National Research Center Journal (2013) 9, 210-215.

[2] Kalpana Kumari, R.Preetha, D. Ramachandran, Vinita Vishwakarma, Rani.P.George, C.Sundaramurthy, U.Kamachi Mudali, C.Sivathanu Pillai. "Nanoparticles for enhancing mechanical properties of fly ash concrete", Materials Today: Proceedings (2016) 3, 2387-2393.

[3] Bertrand Ruot, Arnaud Plassais, Francois Olive, Laurent Guillot, Laurent Bonafous. "TiO2-containing cement pastes and mortars:
Measurements of the photocatalytic efficiency using a rhodamine B-based colourimetric tes”t, Solar Energy (2009) 83, 1794-1801.

[4] Pawel Sikora, Elzbieta Horszczaruk, Teresa Rucinska. "The effect of nanosilica and titanium dioxide on the mechanical and selfcleaning properties of waste-glass cement mortar", Procedia Engineering, Vol. 108 (2015), 146 - 153.

[5] Jay Sorathiya, Dr. Siddharth Shah and Mr. Smit Kacha. "Effect on Addition of Nano Titanium Dioxide $\left(\mathrm{TiO}_{2}\right)$ on Compressive Strength of Cementitious concrete". International Conference on Re-search and Innovations in Science, Engineering \&Technology, Vol. 1 (2017), 219-225.

[6] Jun Chen and Chi-sun Poon. "Photocatalytic construction and building materials: From fundamentals to applications", Building and Environment (2009) 44, 1899-1906.

[7] Andrea Folli, Claus Pade, Tommy Bæk Hansen, Tiziana De Marco, Donald E. Macphee. " $\mathrm{TiO}_{2}$ photocatalysis in a cementitious systems: insights into self-cleaning and depollution chemistry", Cement and Concrete Research (2012) 42, 539-548.

[8] IS 12269 2013- Ordinary Portland Cement-53 Grade-Specification: BIS, New Delhi.

[9] IS 3812 - 2003 - Pulverized Fuel Ash - Specification (Part 2) - For use as admixture in Cement Mortar and Concrete.

[10] IS 383 - 1970 (Reaffirmed 2002) - specification for coarse and fine aggregates from natural sources for concrete.

[11] IS 516 - 1959 (Reaffirmed 2004) - Methods of Tests for Strength of Concrete.

[12] IS 10262 - 2009 Recommended Guidelines for Concrete Mix Designs: New Delhi, India: Bureau of Indian Standards. 